\title{
Para entrar na Casa de Mia Couto em Um rio chamado tempo, uma casa chamada terra.
}

\author{
Ana Paula Valentim Portela
}

\begin{abstract}
RESUMO: Mia Couto nos convida para entrar em seus domínios através do romance Um rio chamado tempo, uma casa chamada terra, com a proposta de nos revelar um espaço mítico, intensamente povoado pelas criações de sua peculiar prosa poética. O resgate das tradições e a apropriação da modernidade erguem-se como dois pólos atraídos por um mesmo centro: NyumbaKaya. Uma análise sobre a personificação desta casa, central ao romance, elucida as forças presentes em elementos que compõem a essência africana: a terra, a mulher, a pátria.
\end{abstract}

ABSTRACT: In the novel Um rio chamado tempo, uma casa chamada terra, Mia Couto invites us to join his world by revealing a mythical space, which is densely inhabited by the creations of his poetical prose. Tradition and modernity are two poles that converge to a common center: NyumbaKaya, a house that plays a central role in the novel. By analyzing the personification of this house, one sees the essential elements of African culture: the land, the woman, the nation.

PALAVRAS-CHAVE: Espaço; tradição; África.

KEYWORDS: Space; tradition, Africa.

\section{Convite para entrar}

O romance Um rio chamado tempo, uma casa chamada terra, do escritor moçambicano Mia Couto narra a história de Marianinho, um jovem que se vê motivado pela morte do avô a retornar à terra natal e às suas raízes para realizar o cerimonial fúnebre do patriarca da família, bem como resgatar sua identidade africana através das lembranças e revelações deste acontecimento.

O centro deste retorno e deste resgate será a casa de seus ancestrais na Ilha de Luardo-Chão, o ponto de partida de sua identificação consigo mesmo dentro daquele universo aparentemente tão distante e tão diferente da cidade, lugar de sua formação, rico em recursos da modernidade, porém infértil para o sustento das tradições.

A relação estabelecida entre a casa e o tempo, declarada pelo próprio título do romance, permeia todas as vertentes da obra, todos os seus personagens e seus espaços. Uma sucessão temporal de eventos, abrigados pela memória dos rituais da tradição

\footnotetext{
${ }^{1}$ Mestranda em Estudos Comparados de Literaturas de Língua Portuguesa, FFLCH-USP.
} 
africana, dentro das visões que Marianinho estabelece em suas visitas, se dá pelo contato do que lhe é natural e sobrenatural, um processo, muitas vezes, afastado dos conceitos de lógica e linearidade da verossimilhança.

Esta ruptura com a linearidade do texto, no uso sensível da prosa poética, é um grande marco da escrita de Mia Couto, apropriando-se da construção do fantástico dentro da realidade de seus personagens e da realidade do próprio leitor. O trabalho "artesanal" de seu léxico é um registro de compromisso com a representação estética do mundo. O uso explícito de criações neológicas ultrapassa o registro do que seria uma linguagem regional e oral, representando, nas mãos do escritor, a exposição de um universo contraditório presente nos países colonizados em África que buscam até hoje, após e até pela Independência, sua identidade.

O tempo e a casa selam uma união conjugal dentro do romance. O tempo, em seu caráter masculino, representa os homens da história. Sofre um processo de desmoronamento (particular à casa) para refletir toda a desconstrução dos homens desta família: suas dependências emocionais, suas ambições sempre volúveis, os desenganos vestidos pela guerra do país e desnudos por uma fome de paz interna e externa insaciável em seus corpos e espíritos.

A casa, o feminino, é habitada pelas mulheres. Precisa de defesa, mas mantém-se altiva pela junção dos vivos e dos mortos no ventre de seus corredores. As revelações que direcionam o desenvolvimento do romance são cozidas, conduzidas e muitas vezes protagonizadas pelas mulheres da família.

A morte de Dito Mariano, patriarca dos Malilanes é a morte da "casa pai" e o nascimento da "casa mãe", responsável pelo abrigo das peças que compõem a identidade de Marianinho mediada pela tradição e pela modernidade de seus valores.

\section{A casa como miragem}

O encontro de Marianinho com a casa é o marco inicial de sua viagem de formação. Voltar a Luar-do-Chão não é propriamente um regresso, mas sim um caminho circular, movimento presente na África moçambicana. Os espaços cidade, ilha e os tempos da 
modernidade e da tradição envolvem uma travessia e não um retorno: "O velho Mariano sabia: quem parte de um lugar tão pequeno, mesmo que volte, nunca retorna". ${ }^{2}$

Em suas palavras descreve a dimensão de estar diante da construção da casa sensorial de seus ancestrais: "Por fim, avisto a nossa casa grande, a maior de toda a Ilha. Chamamo-lhes de Nyumba-Kaya, para satisfazer familiares do Norte e do Sul. "Nyumba" é a palavra para nomear "casa" nas línguas nortenhas. Nos idiomas do Sul, casa se diz "kaya". ${ }^{3}$

A partir do encontro com a casa, Marianinho inicia sua travessia entre os dois mundos ao qual pertence estabelecendo o contato do real com o fantástico: “... Sobre mim se abate uma visão que muito se irá repetir: a casa levantando vôo, igual ao pássaro que Miserinha apontava na praia. E, eu olhando a velha moradia, a nossa Nyumba-Kaya, extinguindo-se nas alturas até não ser mais que nuvem entre nuvens."

A visão da casa no levante de vôo já pressupõe seu espaço como sagrado, onde o processo de desmoronamento do tempo não acontece. No trecho em que é descrito o enterro de Juca Sabão, o coveiro Curozero Muando, seu filho, ao relatar um episódio pessoal de enfrentamento da morte, utiliza-se da mesma imagem alada para a transposição dos estados de vida e morte: “- A gente não vai para o céu. É o oposto: o céu é que nos entra, pulmões adentro. A pessoa morre é engasgada em nuvem." 5

A casa que ascende, transformando-se em nuvem, relaciona-se com a definição dada pelo coveiro para a morte na seguinte composição: a casa que passa a ser nuvem é também o mesmo sopro que entra pelos pulmões, que engasga. $\mathrm{O}$ mesmo espaço onde a vida é provocada é também espaço provocador da morte pela metáfora das nuvens.

Assim como a tradição de se remover o telhado do cômodo ocupado pela morte liga-se à ação do vôo: "Mesmo ao longe, já se nota que tinham mandado tirar o telhado da sala. É assim, em caso de morte. O luto ordena que o céu se adentre nos compartimentos,

\footnotetext{
2 Mia Couto, Um rio chamado tempo, uma casa chamada terra. São Paulo: Companhia das Letras, 2003, p. 45 .

${ }^{3}$ Obra citada, p. 28. Cabe notar as disposições sintáticas dos vocábulos que qualificam a casa: "casa grande" expõe uma função de valor emotivo ao personagem, ao contrário de "grande casa" que poderia apenas remeter a noção espacial de tamanho. Outro ponto levantado neste mesmo trecho é a nominação da casa, NyumbaKaya, por termos do Norte e do Sul do país, evidenciando sua posição de centro e de convergência dos familiares.

${ }^{4}$ COUTO, Mia. Um rio chamado tempo, uma casa chamada terra, p. 29.

${ }^{5}$ COUTO, Mia. Op. Cit. p. 163.
} 
para limpeza das sujidades. A casa é um corpo - o tecto é o que separa a cabeça dos altaneiros céus." ${ }^{\prime 6}$

O movimento de ascensão é comum tanto ao homem (Avô Mariano) quanto a casa. Ambos são corpos em exposição terrestre, sujeitos à metafísica celeste.

\section{A casa como mãe e mulher}

Transgredindo a mera classificação gramatical de substantivo de gênero feminino, a estreita ligação do objeto "casa" ao qualificativo de feminilidade tem por intersecção a condição maternal e sexual do espaço e das relações estabelecidas dentro dele. $\mathrm{O}$ acolhimento residencial advém tanto pela figura de mãe quanto pela figura da mulher.

A “casa-mãe" estabelece vínculos germinais, protetores do alicerce e do crescimento. Duas exposições dentro do romance são pertinentes a esta construção:

"Uma vez mais, matrona e soberana, a Nyumba-Kaya se ergue de encontro ao tempo." e "Vou pelo corredor, alma enroscada, como se a casa fosse um ventre e eu retornasse à primeira interioridade." ${ }^{\prime}$

A “casa-mulher" já é descrita como desafiadora diante dos homens que nela foram gerados e abrigados, tanto em vida quanto em morte. Muitos são os seus caminhos penetráveis e impenetráveis. A porta de entrada, que é o seu quintal, é aberta ao mundo, receptiva, ao alcance dos olhos de quem se aproxima, mesmo de longe.

Sua cozinha, lugar do fogo e da alquimia, localiza-se dentro da construção e não no terreiro de fora, o que normalmente ocorre nas casas africanas. No romance, este fato novo na disposição de um cômodo da casa, não se justifica apenas por uma "ocidentalização arquitetônica". A Nyumba-Kaya, por ser sujeito e não objeto tem um corpo. Um corpo que possui suas entranhas, sendo a cozinha uma delas.

Vista como mulher, é inerente que tenha também seu quarto de segredos, o único que dá vida ao molho de chaves dado pela avó Dulcineusa ao neto. Sendo este o único cômodo que não existe de fato, revela em sua abstração, elementos concretos na reelaboração da história daquela família.

\footnotetext{
${ }^{6}$ COUTO, Mia. Op. Cit. p. 28.

${ }^{7}$ COUTO, Mia. Op. Cit. p. 29.

${ }^{8}$ COUTO, Mia. Op. Cit. p. 111.
} 
A particularidade da casa "mulher feita" é marcada como o único espaço onde o Avô Mariano dormiu. Em suas palavras, ele explora bem a questão da intimidade do sono:

“- Fazer amor sim, e sempre. Dormir com uma mulher, isso é que nunca. E explicava: dormir com alguém é a intimidade maior. Não é fazer amor. Dormir, isso é que é íntimo. Um homem dorme nos braços de mulher e a sua alma se transfere de vez."

A experiência de amor e intimidade contida nas palavras de avô carrega a própria definição da Nyumba-Kaya em seu papel feminino. O contato mais estreito de sua vida e de sua morte foi estabelecido pelo munumuzana somente com a casa, mesmo em relato posterior revelar ter dormido com Admirança, seu grande amor. A diferença aqui se dá por conta das questões "com quem dormiu" e "em quem dormiu". Tanto a casa quanto a tia respondem a primeira, porém a segunda questão só é possível ser respondida pela casa, pois somente nela teve sua alma transferida.

\section{A casa como planta}

A avó Dulcineusa, em sua força de tradição, ensina: "Todos os dias a avó regava a casa como se faz com uma planta. Tudo requer ser aguado, dizia ela. A casa, a estrada, a árvore. E até o rio deve ser regado."10

$\mathrm{Na}$ invocação das raízes desta casa é possível, mais uma vez, estabelecer um elo entre o feminino e o masculino nesta passagem do romance. A avó, figura feminina, transmite a tradição orgânica da relação com a casa. $\mathrm{O}$ ato de regar está vinculado ao ato de alimentar, garantindo a circulação da seiva e da energia do espaço e daqueles que o ocupam, atitude particularmente matriarcal e geradora.

A manutenção deste fluxo estende-se para outros elementos: a estrada, a árvore e o rio. Estes, no contexto de imagem, são por sua vez elementos de alinhamento retilíneo: a estrada e o rio em movimento horizontal (de travessia); a casa e a árvore em movimento vertical (de ascensão).

$\mathrm{O}$ avô, a figura masculina, se remete a imagens semelhantes em sua última carta: "Você, meu neto, cumpriu o ciclo das visitas. E visitou casa, terra, homem, rio: o mesmo ser, só diferindo em nome." 11

\footnotetext{
${ }^{9}$ COUTO, Mia. Op. Cit. p. 46.

${ }^{10}$ COUTO, Mia. Op. Cit.p. 31.
} 
A evocação de vários elementos, iniciada pela casa, remete a tradição citada pela avó, sob a visão patriarcal. Se no primeiro levantamento temos a transmissão que se volta para a terra (a casa como planta), aqui o processo se dá pelo tempo através das visitas do neto no sentido de passagem. Muito mais do que passagem, pode-se tomar tal vivência de Marianinho como uma ultrapassagem de fases: nascimento (casa), crescimento (terra), amadurecimento (homem) e morte (rio).

\section{A defesa da casa}

O embate entre a modernidade e a tradição no romance de Mia Couto é representado pelas figuras de Marianinho e de seu tio Ultímio. Caçula entre os três filhos de Dito Mariano e Dulcineusa, Ultímio seria o ponto final nas descendências das tradições africanas dentro da família (característica demarcada pelo seu próprio nome) e aquele que, pretensiosamente iniciaria o processo de modernização da Ilha. Representa em todas as vertentes, a figura do africano assimilado que lucrou materialmente com a Independência de seu país.

Seu distanciamento em relação às raízes pode ser entendido por seu comportamento diante do cerimonial do enterro do pai e a maneira como se relaciona com as pessoas de Luar-do-Chão, principalmente com seu sobrinho, o único, a seu ver, capaz de entender e apoiar a compra de Nyumba-Kaya, por carregar valores modernos em sua formação.

Quando é revelada a verdadeira filiação de Marianinho ocorre o choque entre o moderno e o tradicional. Sendo filho de Dito Mariano, Ultímio não é mais o último, é o sobrinho quem fecha o ciclo e neste caso já não é mais o valor externo da tradição que permanece.

É inevitável que o moderno adentre as casas, aproprie-se dos costumes e da vida daquelas pessoas. Marianinho, sendo irreconhecível ("Há anos que não visito a Ilha. Vejo que se interrogam: eu, quem sou? Desconhecem-me. Mais do que isso: irreconhecemme"12) acaba sendo o transmissor da modernidade em um ambiente tradicional. O questionamento quem faz, no entanto, não são aqueles que não o reconhecem, é ele mesmo; interpelado pela pontuação da vírgula em seu discurso.

${ }^{11}$ COUTO, Mia. Op. Cit. p. 258.

${ }^{12}$ COUTO, Mia. Op. Cit. p. 29 
As raízes de Marianinho crescem por todo o romance. Quando se reconhece alicerce de Nyumba-Kaya aproxima-se do fim de sua travessia. Este reconhecimento íntimo é explicitado pelo diálogo travado com o tio quando este deseja comprar a casa e o sobrinho assegura que esta nunca será dele: “... porque essa casa sou eu mesmo. O senhor vai ter que me comprar a mim para ganhar posse da casa. E para isso, Tio Ultímio, para isso nenhum dinheiro é bastante." ${ }^{\prime 13}$

A epígrafe que inicia o quarto capítulo condensa justamente a relação da casa com a tradição: “O importante não é a casa onde moramos. Mas onde em nós a casa mora." (Avô Mariano) $)^{14}$

Esta citação, feita pelo homem mais velho da família, exprime bem a relação entre estes dois pólos: da modernidade e da tradição. Sendo a modernidade inevitável em muitos aspectos, cabe a cada um de nós preservarmos os valores históricos e culturais inerentes ao nosso desenvolvimento cognitivo nos espaços que ocupamos.

Em África, a modernidade da cultura branca européia bateu à porta, sem respeito algum, sem se dar conta de que para os povos africanos "quem bate à porta já entrou. E já entrou nesse espaço privado que é o quintal, o recinto mais íntimo de qualquer casa"15. Essa noção de respeito jamais praticada pelos portugueses nos quintais africanos descobre a face de ignorância que envolveu todo o processo de colonização destes países.

\section{A casa como país}

Dentre estas tantas metáforas para a casa, expostas aqui de maneira resumida, a mais forte delas seria esta última, proferida pelo personagem de Fulano Malta, numa discussão com Ultímio sobre os valores da tradição: “... Porque seus filhos são meninos de luxo. Não cabem nesta casa que é o país inteiro." ${ }^{16}$

Uma casa habitada, seja por uma família numerosa, seja por uma única pessoa; nas cidades mais povoadas ou nos campos mais longínquos; é sempre um espaço de história.

\footnotetext{
${ }^{13}$ COUTO, Mia. Op. Cit. p. 249.

${ }^{14}$ COUTO, Mia. Op. Cit.p. 52.

${ }^{15}$ COUTO, Mia. Op. Cit.p. 221.

${ }^{16}$ COUTO, Mia. Op. Cit.p. 77.
} 
Humanas, sociais, culturais, essas histórias são as fotografias do álbum imaginário da avó Dulcineusa, são as plantas regadas do quintal, o milho cozido na cozinha. Elementos que protagonizam tanto a conservação quando a degradação de uma casa.

A casa, com seus moradores e seus visitantes, agüenta-se sobre a terra mesmo com as marcas que o tempo lhe faz. A colonização portuguesa em África está metaforizada em todos esses apontamentos acima. A visita do colonizador violentou o tempo nas marcas que deixou na terra.

Transpostas para a literatura pela linguagem poética e fantástica de Mia Couto, não só neste romance, como em suas demais obras, estas marcas são o registro na história africana dos muros erguidos pela colonização em torno de suas casas sensoriais. Muros de valores pré-concebidos, separatistas da modernidade e da tradição, onde pousam aves personificadas por Marianinho; em busca de identidade através de vôos migratórios. Aves que carregam sementes ancestrais na intenção de germinar algum futuro nos quintais de seu país.

\section{Referências bibliográficas}

COUTO, Mia. Um rio chamado tempo, uma casa chamada terra. São Paulo: Companhia das Letras, 2003. 